\title{
APPLYING THE AWARENESS OF ENVIRONMENTAL PROTECTION INTO THE CURRICULUM FOR PRIMARY SCHOOL STUDENTS IN VIETNAM VIA PRACTICAL ACTIVITIES
}

\author{
Nguyen Tan Danh \\ FPT University, Vietnam \\ Corresponding Author: nguyentandanh0774@gmail.com
}

\begin{abstract}
Our living environment is increasingly polluted, not only because the amount of resources is increasingly being indiscriminately exploited, there are still many forms of production that pollute the environment, toxic substances which are difficult to decompose into the environment because of not-good human consciousness of some people. The improper collection and classification of daily-life waste is an issue that needs to be addressed. Besides, the situation of indiscriminate garbage disposal and many serious environmental pollution points is formed. Some people even bring domestic waste, dead animal carcasses to rivers and lakes right where they live. Facing the increasing risks of natural environmental pollution, Vietnam needs to promote the education of environmental protection awareness for all people in general and primary school students in particular. Students are the future generation of the country, are the decisive owners for the development of the whole society and are also the people most affected by natural resources and the environment. The article uses survey methods and analyzes data from journals and recent studies. The results show that we need to take action today so that students feel responsible for protecting resources and the environment for a clean and green world.
\end{abstract}

KEYWORDS: Awareness, students, environment, protection.

\section{Introduction}

To protect, preserve and promote the values of national cultural heritage, Vietnam has achieved many outstanding achievements, many of which are of international significance, thanks to the effective use of tourism activities [1].

Currently, environmental pollution is one of the global problems. In Vietnam, half of rivers, wetlands and beaches have been polluted and $70 \%$ of rural craft villages are at risk regarding serious pollution. Along with that, the sea water intrusion into the mainland; Barren land, barren hills and the degradation of plant and animal genetic resources are on the rise [2].
In order to overcome the environmental pollution, it is necessary to raise the awareness of environmental protection for everyone, including the awareness of environmental protection for primary school students [1]. The article analyzes the current situation of educating the awareness of environmental protection for primary school students in schools, pointing out its limitations and shortcomings; proposing a number of solutions to promote the education of environmental awareness awareness for primary school students today in Vietnam [3].

\section{Status of Environmental Awareness Education For Primary School Students In recent years, the development of environmental awareness educational content, programs and materials for primary school students in Vietnam has made significant progress, following a fairly coherent process, and stick to the reality of the country [3]. In fact, in Vietnam, there are no specific subjects on environmental protection awareness for primary school, only books on environmental protection of the core subjects and educational materials for environmental protection through extracurricular educational activities. The awareness of protection is only taught integrated, integrated into a number of subjects (such as ethics, natural and social, language, Vietnamese, science, history and geography, etc.) and via extra-curricular activities [4].}

Contents and education programs on environmental protection awareness for primary school students have a reasonable duration, basic and necessary knowledge, and integrate into other subjects suitable for the program, not just stay at basic knowledge about the environment and environmental protection, but also create opportunities for primary school students to express their ability to explore and explore nature [2]. In addition, primary school teachers flexibly apply many modern teaching methods, teaching in a positive pedagogical direction, combined with traditional teaching methods and modern teaching facilities. 
Most elementary school leaders and teachers are aware of the importance of educating the awareness of environmental protection for primary students. The school leaders focus on researching and organizing to thoroughly grasp the country's undertakings and guidelines and the State's policies and laws in many forms such as exams to learn about the law, the environment, and thematic activities, good communicator, pedagogical council meeting, etc. Most teachers accept proper environmental awareness and the importance of environmental protection, first of all to preserve, prevent and limit negative impacts on the environment, respond to environmental incidents, overcome pollution, degenerate, improve, restore the environment, etc.

In fact, they are aware that they must have extensive knowledge and expertise to transmit achieve all the content of educating the awareness of environmental protection for students, because that way, the quality and efficiency will be achieved [5]. They are aware that, in the face of potential, challenging and unforeseen dangers due to the current pollution of natural resources, the education on awareness of environmental protection must begin at the age of primary school students [3].

They found that environmental pollution is caused by humans. This situation is exacerbated when the population grows rapidly and poverty has not been pushed back [1]. They identified educational goals, the most effective way to educate the awareness of environmental protection for primary school students through the mainstream subjects (such as Vietnamese, ethical, scientific, natural and social, historical and geographic, etc.).

They also realized that it is necessary to educate about the awareness of environmental protection for primary school students through extra-curricular activities such as young bamboo broadcasts, through sightseeing tours scenes, historical sites, tree planting, scavenging, etc. This is effective because it complements, reinforces theoretical knowledge learned in subjects and contributes to the formation of attitudes and practice. vi, environmental protection skills for primary school students. They recognize the need to closely combine the awareness of environmental protection for students through core subjects and extracurricular educational activities to supplement knowledge between theory and practice [6].

\section{Methodology and Results}

This article is done with the support of 100 primary school students at the two schools above in the suburbs of Ho Chi Minh City. The implementation time is in January. The reason why the author chose this place to conduct the survey is because their awareness of environmental protection is not good, in fact, this area is polluted but is not paid much attention. In addition, the survey locations also have many advantages because these two schools are not far from the city center. Paper survey is conducted with some simple questions to help students answer most easily. In addition, face-to-face interviews were also conducted with a number of students and teachers.

Question1: Are you regularly educated about pollution at school?

Question 2: Are you regularly educated about pollution at home?

Question 3: Do you often throw trash on the street or somewhere other than the trash?

Question 4: How often do you watch environmental education programs on TV?

Educating about environmental protection through core subjects and outside class hours has raised students' awareness of environmental protection. The children have generally understood that the cause of environmental pollution is due to human ignorance. Primary school students also know that protecting the environment is not only about keeping the environment fresh, but also keeping natural resources, minimizing the harmful effects of climate change [7]. Though direct interviews, the majority of primary school students had their protests against actions that pollute the environment such as littering, picking flowers, breaking branches, catching birds, cutting forests; actively support positive actions to protect the environment at school and locally [4]. They also participate in planting trees on campus and creating beautiful scenes for the school.

Although environmental education has been being emphasized in educational programs, there are still some students who are not fully aware of the role of this education. A few children (3\%) still choose "Never", this proves that the sense of environmental protection of a part of students still needs to be considered (Question 1). Not only school, but also the family plays an important role. There are some children $(11 \%)$ who choose "Sometimes", which is of great concern because the family's concern with their children about environmental awareness education is so important (Question 2). 


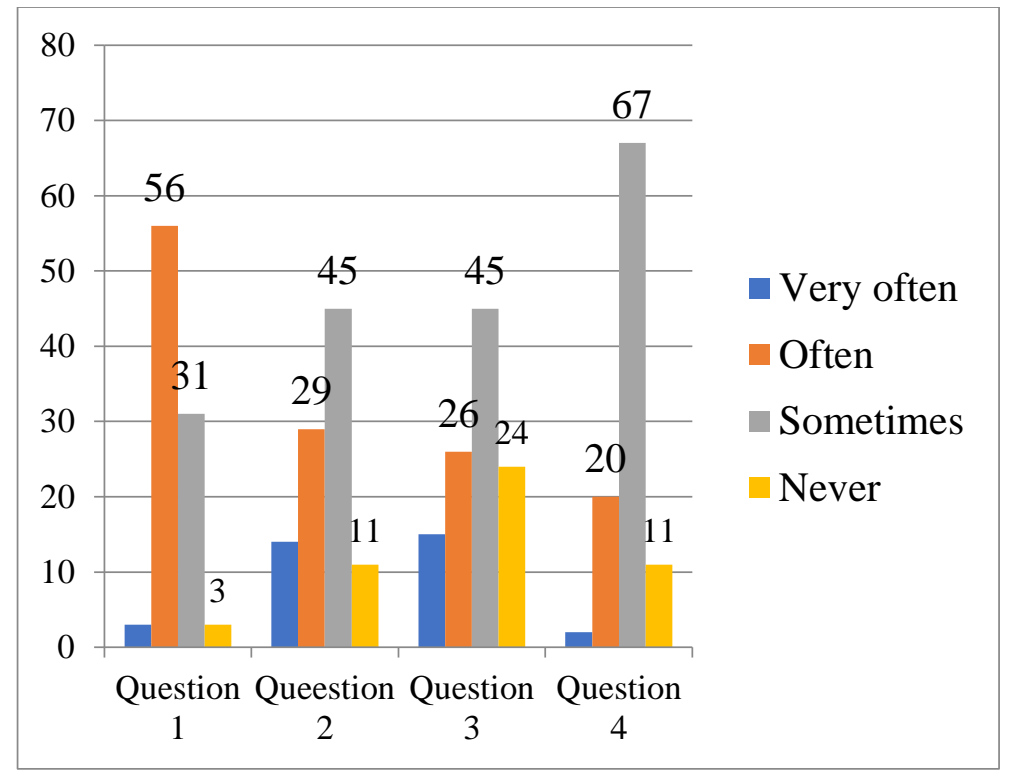

Figure 1. Primary school students' education about the environment

And it is not surprising that some children are still not aware of the role of trash cans. In question 3, this once again reminds us to have a little deep concern about this bad habit of children who chose "Never" (24\%), we need to form good habits for them as soon as possible. For question 4, TV programs related to the sense of environmental protection also need to be paid more attention to, this affects their perception a lot instead of watching cartoons or entertainment programs. Mind, they also need to pay attention to meaningful programs to protect the environment. (Figure 1).
The results also shows that the majority of primary school students know how to show a critical attitude towards deforestation, burning forests for slash-andburn cultivation, because these actions harm the environment, lead to droughts, floods, and environmental damage. nature.

Most primary school students initially have a correct and clear attitude towards unethical phenomena, violate the law on the environment and have a pure and healthy affection for their homeland and country work to protect environment (Figure 2).

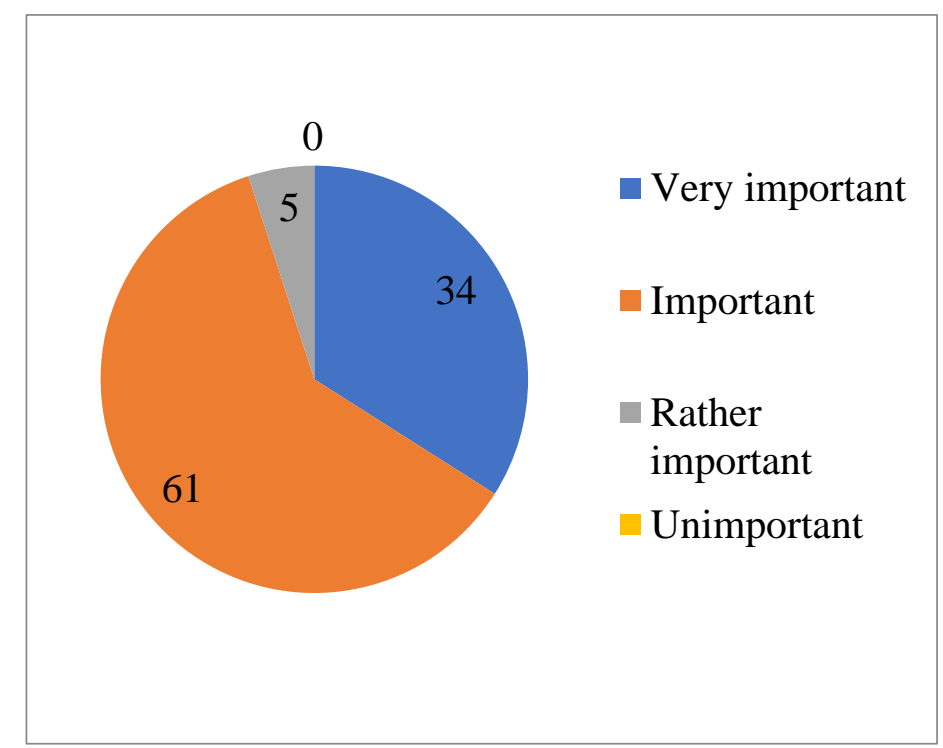

Figure 2. The importance of environmental protection

Self-discipline and voluntary participation in environmental protection activities are the most basic characteristic of primary school students' behaviors to protect the environment, emotional manifestations of their care for the environment. Nature [3]. They actively responded and participated in the school's environmental protection movements. Most elementary school students affirmed that to contribute to environmental protection, it is necessary to have specific behaviors such as not disposing of rubbish on school grounds. 
Over the past years, primary schools across the country have focused on educating primary students to have awareness, right attitudes, a sense of responsibility and form positive behaviors in protecting the environment. at the same time, show condemnation and protest against acts of intentionally polluting the environment, causing bad harm to the environment.

Through the core subjects, teachers have persisted in implementing the task of integrating and integrating the content of educating the awareness of environmental protection for students; for knowledge about the environment and environmental protection not confined to a specific subject but in subjects such as ethics, Vietnamese language, nature and society, fine arts, science, music, history and geography. Each subject has very rich content and has own strengths in educating the awareness of environmental protection for primary school students [6].

Through extracurricular educational activities, students have the opportunity to understand the environment, protect the environment and explore nature to supplement their knowledge in the curriculum. They have strengthened their knowledge, expanded their knowledge, practiced environmental protection skills, formed initiative, creativity, and skills to solve environmental problems and environmental pollution. Out-of-class-time educational activities for primary school students on environmental protection are increasingly diversified, rich and effective.

In general, the education of environmental protection awareness for primary school students has been paid attention by the school and teachers and implemented in many forms, initially bringing about results.

\section{Limitations In The Education of Environmental Awareness For Primary School Students}

Firstly, the State's legal policies on the education of awareness of environmental protection for primary school students has not been synchronous and timely. Although the State and the Ministry of Education and Training has focused on raising awareness of environmental protection for primary school students, but in many primary schools, implementing environmental awareness education for students. Primary school students (from grade 1 to grade 5) were not synchronous and timely. Therefore, the contingent of teachers and primary school students face many difficulties in implementing environmental awareness awareness education for students [5].

Second, the capacity of many teachers to educate about environmental protection awareness is still limited. In some primary schools, the qualifications of the teachers are not equal; A part of contract teachers is not enthusiastic about the profession, has not been fostered with knowledge about the environment and environmental protection, has not accumulated and updated new knowledge about the environment and environmental protection [7].

That leads to the situation that primary school students lack knowledge about the environment and protect the environment. The training and fostering of knowledge about the environment and environmental protection for teachers have not been carried out regularly, sometimes still in form. Many teachers have not actively participated in training courses on environmental knowledge and environmental protection; do not know how to integrate and integrate the content of educating the awareness of environmental protection for primary students through core subjects and extracurricular educational activities [8]. The preparation of integrated teaching and integration of content of environmental protection education is still sketchy, has no focus, focus, not specific, yet clearly, also of a general nature, to deal with. Teachers are not really a good example in protecting the environment for students to follow [9]. The education of environmental protection awareness for students is still scattered romantic, the form has not gone into focus yet. This has a significant impact on the quality and effectiveness of educating the awareness of environmental protection for primary students.

Third, the contents, programs and methods of educating the awareness of environmental protection for primary school students still have many shortcomings [3]. Contents and programs of educating the awareness of environmental protection for primary school students are general, sketchy, and have not yet reached the depth of knowledge of the environment and environmental protection. The amount of time devoted to environmental awareness education is too little. Contents, education programs on environmental protection awareness, put pressure on both teachers and students [8].

The renewal of the method of educating the awareness of environmental protection for primary school students has not really changed. The main method is widely used by teachers in educating about sense of environment protection [9]. ent for primary school students is still a traditional method, less associated with real social life, heavily equipped with knowledge of the subject, but has not focused on educating attitudes, behaviors and life skills. Besides, the ability of many teachers to use information technology in teaching in general and educating about the awareness of environmental protection for primary school students in particular is still weak [10]. 
Fourthly, the education of environmental protection awareness for primary school students at school is still formalistic, perfunctory, through loudspeaker, far from reality [2]. One of the basic reasons that make primary school students, parents and society overlook the content of environmental protection awareness education is that the lecture content is not really associated with reality and lacks attractiveness. The integration and integration of the content of environmental protection awareness education into the core subjects is still sketchy, formal and standard. Teachers only consider this as a mandatory requirement in the chapter submitting it without viewing it is truly essential and important. The implementation of lectures through the main subjects has not been seriously invested and creative.

Some schools also consider the content of educating the awareness of environmental protection as an extra part, not important. The activities of educating the awareness of environmental protection through outof-class-time education do not have close coordination between schools and unions; On the other hand, the lack of knowledge and skills of this team is a huge barrier in educating students about environmental protection, so it is often effective.

Some schools develop plans to organize movements only in form, deal with routine; This leads to a situation that a large part of students are indifferent, do not participate or just participate because they are afraid of being deducted from competition points, so the results of movements and competitions have not really brought high efficiency.

\section{Solutions to Enhance Education On Environmental Protection Awareness For Primary School Students}

Firstly, it is necessary to focus on training and fostering in terms of expertise, content, methods and teaching skills for teachers of educating teachers on environmental protection awareness [3]. Training and retraining for primary school teachers should focus on basic contents: improving knowledge, innovating teaching methods, training professional ethics and improving social responsibility. Primary schools need to develop specific and clear training plans on the implementation of environmental knowledge, environmental protection, methods, skills and measures to educate the environmental awareness of the teachers [10]. At the same time, primary schools need to choose qualified, capable and excellent teachers to train and foster into teachers with deep knowledge of the environment or to become experts. in the environmental field.

In addition to the training and fostering of the content, teachers should be equipped with appropriate teaching methods, including: integrated methods, integrating knowledge of environmental protection awareness for primary school students through subjects and through extra-curricular activities, question and answer methods, visual methods, discussion methods and games, extracurricular methods, etc. These methods not only help students to test knowledge learned in class, but also delving deeply into the nature of the phenomenon, of the environment, understanding the interplay between humans and the environment, thereby helping elementary school students to be aware and responsible in protecting the environment [5].

Secondly, renewing the content, educating programs on environmental protection awareness for primary school students should be taken into consideration [8]. We need to develope contents and programs to educate about environmental protection awareness for primary school students in the direction of enhancing integration, then incorporate a number of closely related, closely related contents of the subjects and outside activities, more importantly, we need to form a collective capacity in awareness and how to solve problems in the current environment of life for our students [6].

Third is to renew methods of educating the awareness of environmental protection for primary school students [1]. We need to strongly renovate teaching and learning methods, educating the awareness of environmental protection in the direction of shifting from one-way communication, remembering machines to focusing on teaching, thinking and selflearning, self-discovery and self-study. discovering and promoting positivity, initiative, creativity and student-centered, teachers are only instructive instructors. When renewing the method of educating the awareness of environmental protection for primary school students in the main school hours, teachers need to harmonize traditional methods with modern teaching methods, and need to limit traditional method in a one-way monologue, it is necessary to strengthen group discussion methods and case handling; need to change the mindset from teacher-centered to student-centered [11].

Fourth, we need to educate about the awareness of environmental protection for primary school students through out-of-class-hour educational activities. That means we should increase educational activities outside of class hours [12]. That will contribute to consolidating knowledge learned in the course, expanding knowledge, training skills to protect the environment through the exchange and communication between collectives and society; from there, forming for primary school students the initiative, creativity, skills and ability to solve environmental problems and environmental pollution. 


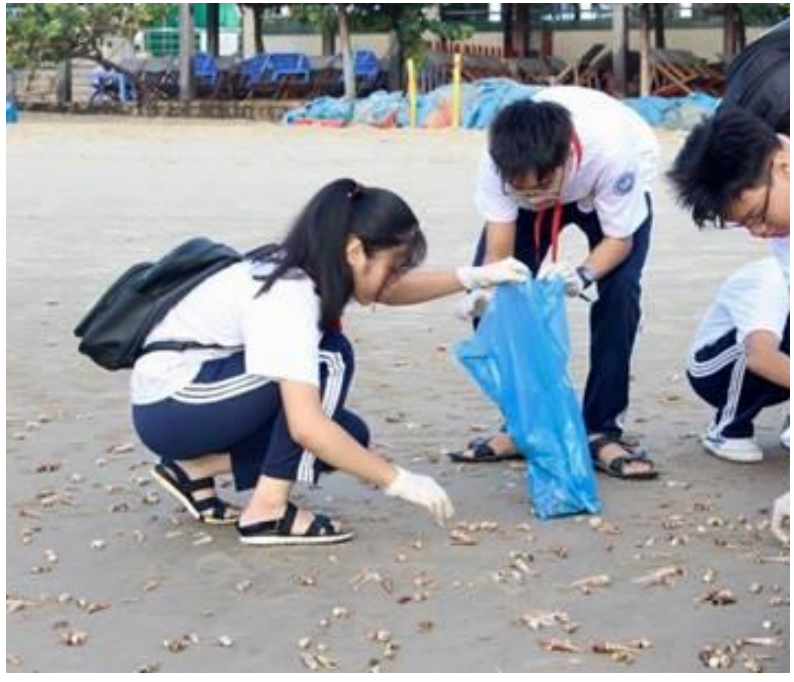

Figure 3. Extracurricular educational activities regarding environmental protection

Extracurricular educational activities in elementary schools need to be rich. Unlike class hours, afterschool educational activities in elementary schools are open, have a vibrant, free atmosphere and promote a positive and proactive character of each student. Therefore, this activity will create excitement and voluntary participation of children in environmental protection (Figure 3).

In order to protect the environment during class time, mainly impart theoretical knowledge, out-of-classhour educational activities will improve the ability of practical activities, turn primary school students' perception into actions help improve the surroundings [8]. Out-of-class educational activities are also favorable conditions and suitable to the needs of primary school students to participate in collective activities. Various forms of after-school activities help convey educational content, especially environmental protection education, to primary school students in a gentle, natural and attractive way [9].

Fifth, it is necessary to equip necessary material and technical facilities to serve the education of awareness of environmental protection [4]. School administrators should encourage and create favorable material - technical conditions as well as time for teachers to participate in training to improve their language skills, informatics, knowledge of teaching theory, scientific knowledge about the environment and environmental protection [7]. On the basis of mastering teaching content, methods, competencies and skills, teachers need to combine modern teaching facilities.

\section{Conclusion}

Climate change is an issue of global concern and protecting the environment more than ever has become an urgent task for no one. Environmental education can start from small things and teachers should integrate into the lecture on current environmental situation, specific measures to protect the environment. Not only on the lecture, if in daily life, the teachers pioneered energy saving, waste classification, etc. efficiency will be doubled. Teachers can set an example for students by not smoking in schools. Not only calling and modeling, teachers should encourage students to self-monitor the protection of each other's environment. The article mentions the role of environmental protection not only of an individual, but of the whole society, and especially the concern of families and schools for children. If we pay more attention to this, then environmental protection is not only a theory but a practical and feasible action for a more friendly environment.

\section{Acknowledgement}

The paper is completed thanks to the kind support of the colleagues as well as the students.

\section{Conflict of interest}

No conflict of interest is noted in the paper.

\section{References}

1. Omoogun, A. C., Egbonyi, E. E., \& Onnoghen, U. N. (2016). From Environmental Awareness to Environmental Responsibility: Towards a Stewardship Curriculum. Journal of Educational Issues, 2(2), 60-72.

2. Strong, C. (1998). The impact of environmental education on children's knowledge and awareness of environmental concerns. Marketing Intelligence \& Planning.

3. Tan, H. H. (2021). Environmental education for the sustainable development of suburban communities in Ho Chi Minh City. In E3S Web of Conferences (Vol. 234). EDP Sciences.

4. Littledyke, M. (2008). Science education for environmental awareness: approaches to integrating cognitive and affective domains. Environmental education research, 14(1), 1-17.

5. Tan, D. N. (2021). Current situation and awareness of pesticide abuse in agriculture in Vietnam. In E3S Web of Conferences (Vol. 234). EDP Sciences.

6. Erdoğan, M., Kostova, Z., \& Marcinkowski, T. (2009). Components of environmental literacy in elementary science education curriculum in Bulgaria and Turkey. Eurasia Journal of Mathematics, Science and Technology Education, 5(1), 15-26.

7. Sadikov, R. M. (2021). The Use Of B. Bloom's Taxonomy Of Educational Goals Of In The Formation Of Linguo-Methodical 
Competences Of Future Primary School Teachers. Journal of Contemporary Issues in Business and Government, 27(1), 349354.

8. Gia, B. H. (2021). Some solutions for sustainable agricultural tourism development in the Mekong Delta in Vietnam. In E3S Web of Conferences (Vol. 234, p. 00063). EDP Sciences.

9. Wen, W. C., \& Lu, S. Y. (2013). Marine environmental protection knowledge, attitudes, behaviors, and curricular involvement of Taiwanese primary school students in senior grades. Environmental Education Research, 19(5), 600-619.

10. Hoi, H. T., \& Danh, N. T. (2020). Greening Houses in the Age of Climate Change. In IOP Conference Series: Earth and Environmental Science (Vol. 505, No. 1, p. 012016). IOP Publishing.

11. Shanka, T. (2000). International students' perception of rural Western Australia as a tourist destination. journal of Contemporary Issues in Business and Government, 6(1), 41-48.

12. Kurbonova, G., Ruzmetova, X., Jumaev, A., \& Yarashev, S. (2021). Development Of Social Activity In Students Of Higher Educational Institutions. Journal of Contemporary Issues in Business and Government, 27(1), 342-348. 